\title{
DOE/BC/15024-02
}

\section{Design and Development of Gas-Liquid Cylindrical Cyclone Compact Separators for Three-Phase Flow}

\author{
Quarterly Report \\ January 1 - March 31, 1998 \\ RECEIVEO \\ AUG 101998 \\ $0 \$ 7$ \\ By: \\ Ram S. Mohan \\ Ovadia Shoham
}

Work Performed Under Contract No.: DE-FG26-97BC15024

For

U.S. Department of Energy

Office of Fossil Energy

Federal Energy Technology Center

P.O. Box 880

Morgantown, West Virginia 26507-0880

By

The University of Tulsa

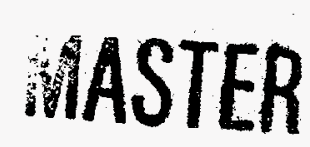

L169 Keplinger Hall 600 South College Avenue

Tulsa, Oklahoma 74104-3189 


\section{Disclaimer}

This report was prepared as an account of work sponsored by an agency of the United States Government. Neither the United States Government nor any agency thereof, nor any of their employees, makes any warranty, express or implied, or assumes any legal liability or responsibility for the accuracy, completeness, or usefulness of any information, apparatus, product, or process disclosed, or represents that its use would not infringe privately owed rights. Reference herein to any specific commercial product, process, or service by trade name, trademark, manufacturer, or otherwise does not necessarily constitute or imply its endorsement, recommendation, or favoring by the United States Government or any agency thereof. The views and opinions of authors expressed herein do not necessarily state or reflect those of the United States Government or any agency thereof. 


\section{DISCLAIMER}

Portions of this document may be illegible electronic image products. Images are produced from the best available original document. 


\section{Disclaimer}

This report was prepared as an account of work sponsored by an agency of the United States Government. Neither the United States Government nor any agency thereof, nor any of their employees, makes any warranty, express or implied, or assumes any legal liability or responsibility for the accuracy, completeness or usefulness of any information, apparatus, product, or process disclosed, or represents that its use would not infringe privately owned rights. Reference herein to any specific commercial product, process, or service by trade name, trademark, manufacturer, or otherwise does not necessarily constitute or imply its endorsement, recommendation, or favoring by the United States Government or any agency thereof. The views and opinions of authors expressed herein do not necessarily state or reflect those of the United States Government or any agency thereof.

\section{Executive Summary}

The objective of this five-year project (October, 1997 - September, 2002) is to expand the current research activities of Tulsa University Separation Technology Projects (TUSTP) to multiphase oil/water/gas separation. This project will be executed in two phases. Phase I (1997 - 2000) will focus on the investigations of the complex multiphase hydrodynamic flow behavior in a three-phase Gas-Liquid Cylindrical Cyclone (GLCC) Separator. The activities of this phase will include the development of a mechanistic model, a computational fluid dynamics (CFD) simulator, and detailed experimentation on the threephase GLCC. The experimental and CFD simulation results will be suitably integrated with the mechanistic model. In Phase II (2000 - 2002), the developed GLCC separator will be tested under high pressure and real crudes conditions. This is crucial for validating the GLCC design for field application and facilitating easy and rapid technology deployment. Design criteria for industrial applications will be developed based on these results and will be incorporated into the mechanistic model by TUSTP.

This report presents a brief overview of the activities and tasks accomplished during the second quarter (January 1, 1998 - March 30, 1998) of the budget period (October 1, 1997 - September 30, 1998). The total tasks of the budget period are given initially, followed by the technical and scientific results achieved. A brief statement on the project work planned for the next quarter concludes the report.

\section{Tasks of the Current Budget Period (Oct. 1, 1997-Sept. 31, 1998)}

\section{Objective: Initial Modeling and Data Acquisition:}

a. Initial development of the mechanistic model for three-phase separation.

b. Design and expansion of two-phase test facility for three-phase loop.

c. Preliminary experimental data acquisition of global separation efficiency.

d. Simulation of three-phase flow using CFX code.

e. Interim reports preparation. 


\section{Technical and Scientific Results Achieved in the Reporting Period}

(January 1, 1998 - March 30, 1998)

As a part of the tasks of the current budget period, the following specific activities have been completed:

1. Started activities for construction of the three-phase flow loop. Updated the preliminary floor layout drawing to scale of the three-phase flow loop consisting of the metering section, test section and, related valves and fittings.

2. Identified a third graduate student to perform the research and experiments.

3. Items for the flow loop partially received. Started procurement of components needed for the flow loop such as pipes and fittings, gate valves, storage tanks, conventional threephase separators, pumps, control valves and test GLCCs.

4. Started development activities to identify strategies for mechanistic modeling for multiphase flow behavior in GLCC. Literature review in progress to identify the issues related to behavior of oil-in-water and water-in-oil dispersions.

A preliminary schematic of the floor layout and the modified layout to scale of the three-phase flow loop consisting of the metering and test section are shown in Figs. 1, 2(a) and 2(b). Air is supplied from a compressor and is stored in a high- pressure gas tank. The air flows through a metering section consisting of micro-motion mass flow meter and control valves. The liquid phases (water and oil) are pumped from the respective storage tanks and are metered with two sets of micro-motion mass flow meters and control valves, before being mixed. The liquid and gas phases are then mixed at a tee junction and sent to the test section. The test section consists of 2 dual stage GLCCs. Initially the test section will be equipped with one dual stage GLCC and later it will be upgraded to 2 dual stage GLCCs. The threephases from the GLCC outlets will also metered using micro-motion mass flow meters. The test section construction will be modular so that in place of GLCC any other separator such as hydro-cyclones could be used in series to form a compact separation system. Control valves placed along the line control the flow into and out of the test sections. The flow loop is also equipped with several temperature sensors and pressure transducers for measurement of the in-situ pressure and temperature conditions.

Two types of GLCC configurations will be considered namely single stage GLCC and dual stage GLCC. The above flow loop can be used for both configurations. These two types of configurations will aid in investigating the function of GLCC as a bulk separator and a full separator. Non-emulsifying oil will be used as the experimental fluid. Flow runs will be conducted initially by using oil-water two-phase and gas will be added as the third phase later. Two types of oil-water interface are possible as shown in Fig. 3. Initial investigation will focus on identifying the nature of oil-water interface and formulate appropriate separation strategies for the GLCC. 
Items already Received for the Flow Loop

1. Micro-motion mass flow meters (Elite type) - 6

2. Transmitters for micro-motion mass flow meters - 6

3. Computers -2

Procurement action initiated for the following items:

1. Pressure Transducers

$-12$

2. Temperature Sensor and Transmitters

$-6$

3. Data communicator

$-1$

4. Data Acquisition System

$-1$

5. Conventional Three-Phase horizontal separator

$-1$

6. Storage tanks for oil and water

$-2$

\section{Project Work Planned for the next Quarter (Reporting Period)}

The following activities have been identified for the next reporting period:

1. Procurement of the following items:

- Upstream Control Valves

- Downstream Control Valves

- PID Controllers

- Pumps for oil and water

- Pipes and Fittings

- Gate Valves

- Test GLCCs

- Laser printer

2. Construction of the three-phase flow loop.

3. Formulation of preliminary experimental plan

4. Development of Preliminary Modeling Strategies for the mechanistic model

5. Formulation of Modeling Strategies for three-phase flow computational fluid dynamic (CFD) simulation. 
曾胥

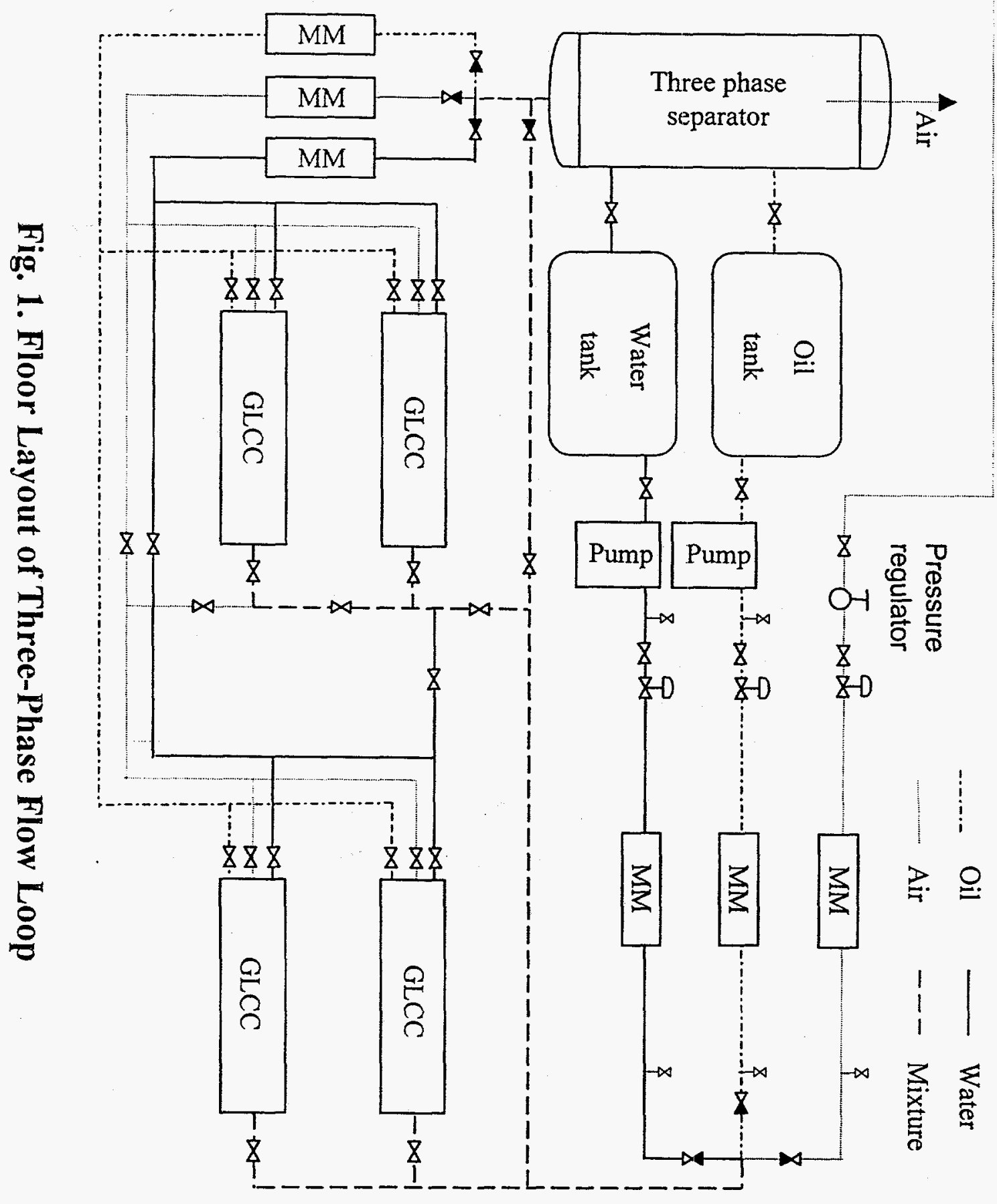




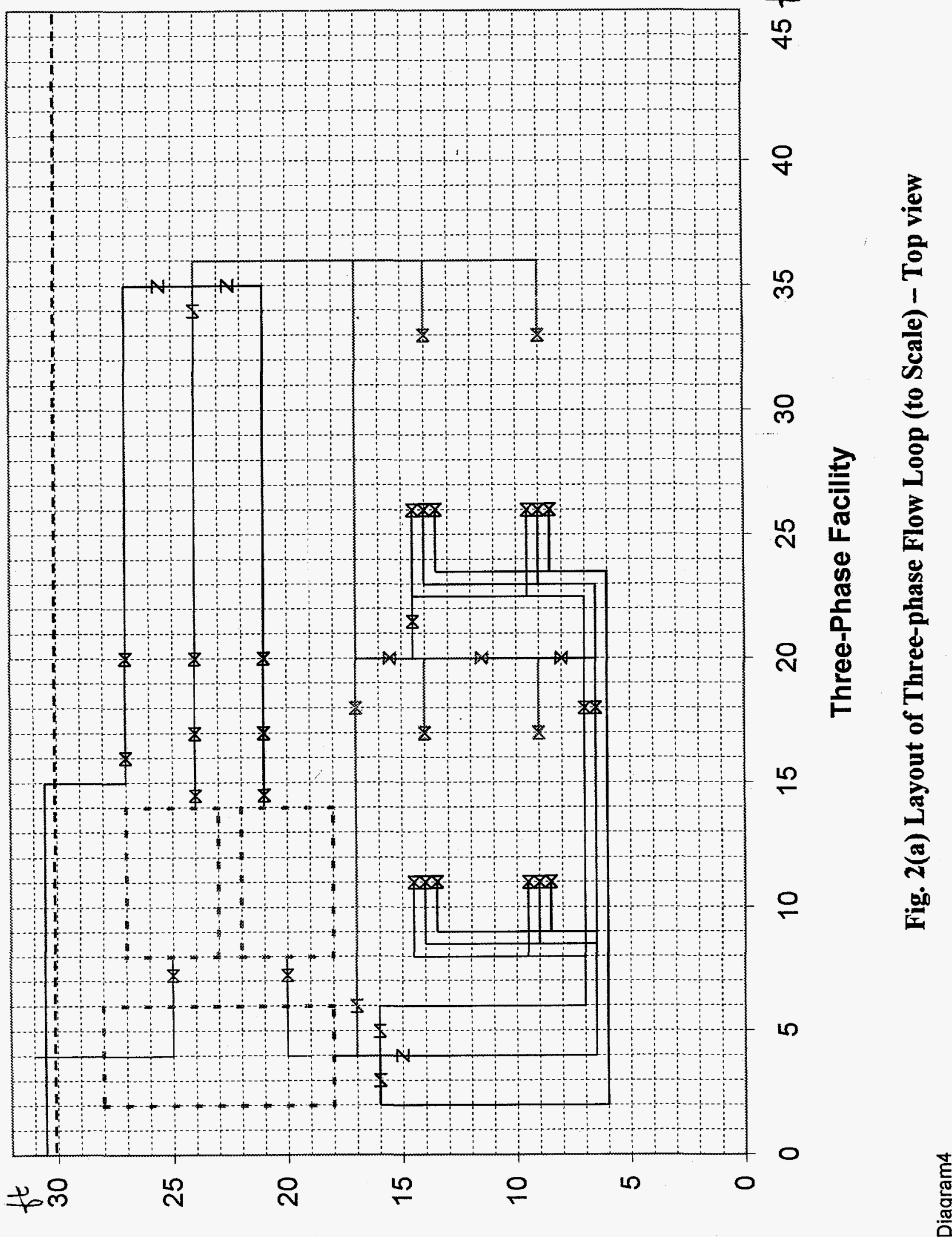




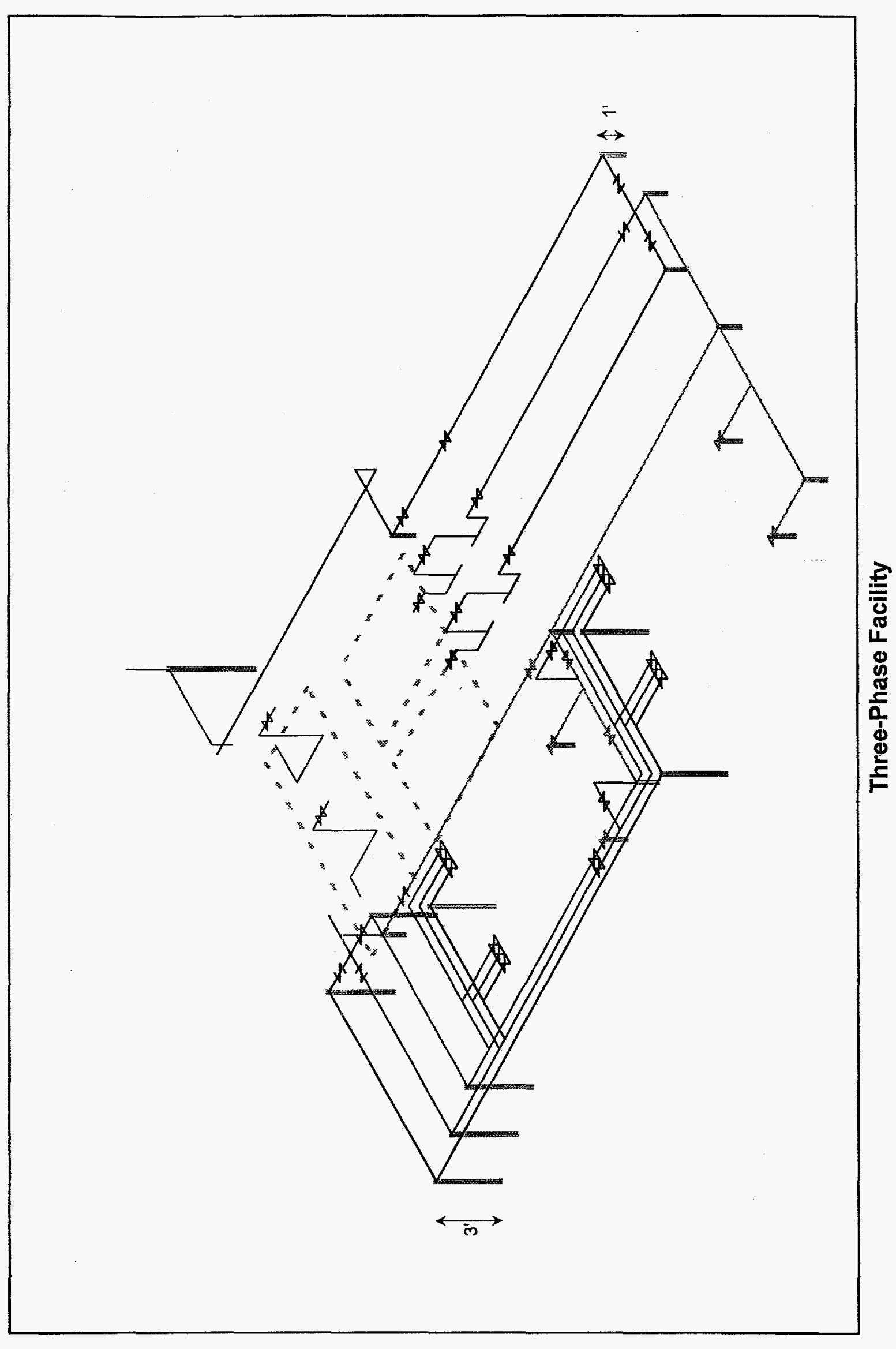

ฟै

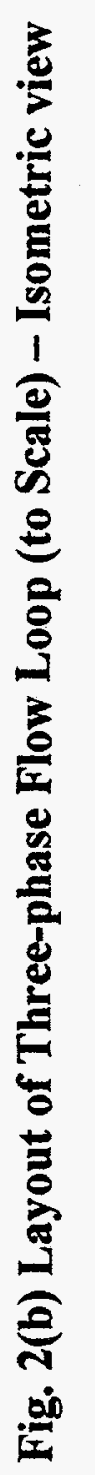

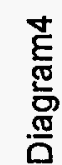


$\because \cdots$

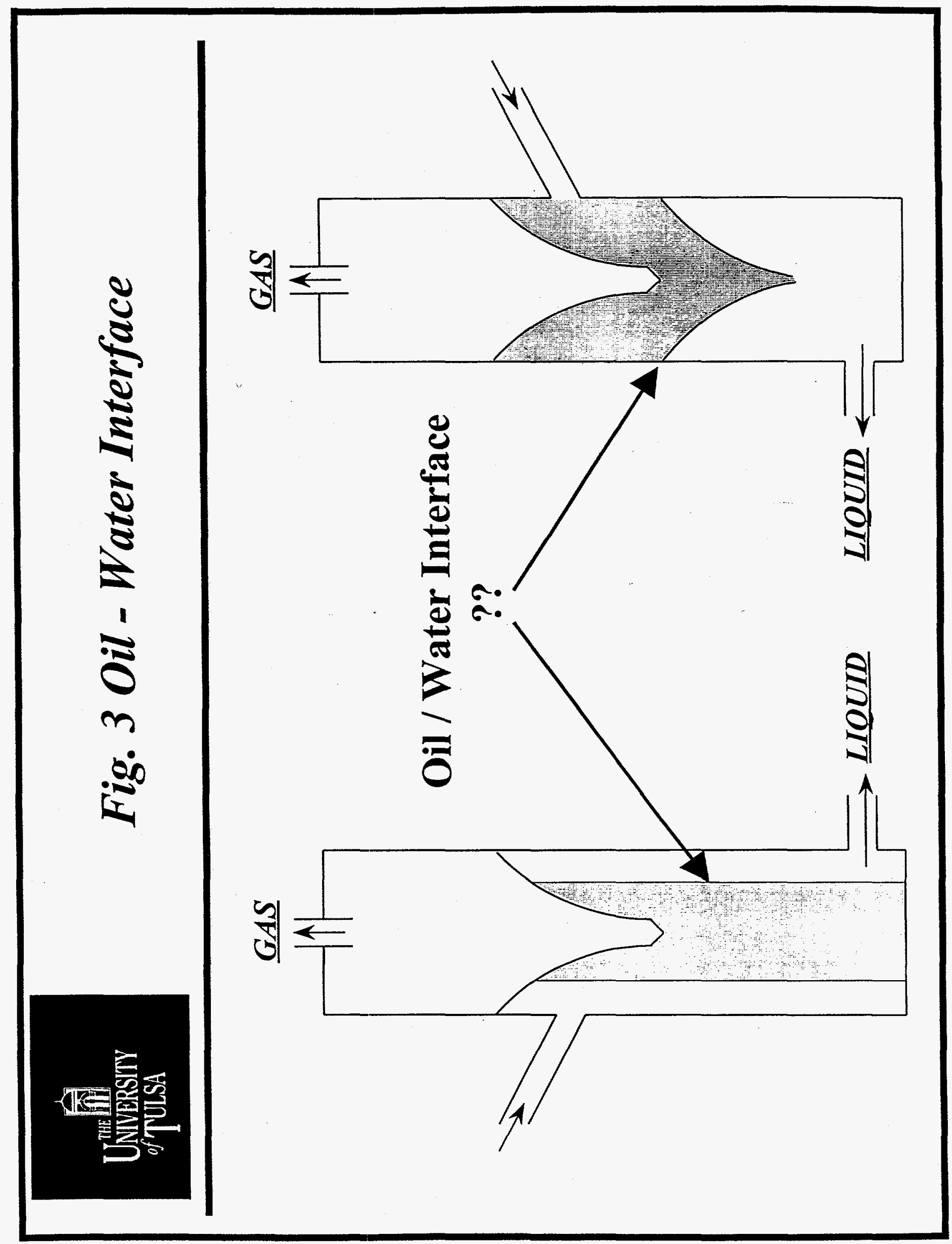

